\title{
Neurotrophin-3 Enhances the Synaptic Organizing Function of TrkC-Protein Tyrosine Phosphatase $\sigma$ in Rat Hippocampal Neurons
}

\author{
Ina Ammendrup-Johnsen, ${ }^{1}$ Yusuke Naito, ${ }^{2}$ Ann Marie Craig, ${ }^{1}$ and ${ }^{\circ}$ Hideto Takahashi ${ }^{2,3,4}$ \\ ${ }^{1}$ Brain Research Centre and Department of Psychiatry, University of British Columbia, Vancouver, British Columbia V6T 2B5, Canada, ${ }^{2}$ Institut de \\ Recherches Cliniques de Montréal, Montreal, Quebec H2W 1R7, Canada, ${ }^{3}$ Department of Medicine, Université de Montréal, Montreal, Quebec H3T 1J4, \\ Canada, and ${ }^{4}$ Division of Experimental Medicine, McGill University, Montreal, Quebec H3A 0G4, Canada
}

Neurotrophin-3 (NT-3) and its high-affinity receptor TrkC play crucial trophic roles in neuronal differentiation, axon outgrowth, and synapse development and plasticity in the nervous system. We demonstrated previously that postsynaptic TrkC functions as a glutamatergic synapse-inducing (synaptogenic) cell adhesion molecule trans-interacting with presynaptic protein tyrosine phosphatase $\sigma$ $(\mathrm{PTP} \sigma)$. Given that NT-3 and PTP $\sigma$ bind distinct domains of the TrkC extracellular region, here we tested the hypothesis that NT-3 modulates TrkC/PTP $\sigma$ binding and synaptogenic activity. NT-3 enhanced PTP $\sigma$ binding to cell surface-expressed TrkC and facilitated the presynapse-inducing activity of TrkC in rat hippocampal neurons. Imaging of recycling presynaptic vesicles combined with TrkC knockdown and rescue approaches demonstrated that NT-3 rapidly potentiates presynaptic function via binding endogenous postsynaptic TrkC in a tyrosine kinase-independent manner. Thus, NT-3 positively modulates the TrkC-PTP $\sigma$ complex for glutamatergic presynaptic assembly and function independently from TrkC kinase activation. Our findings provide new insight into synaptic roles of neurotrophin signaling and mechanisms controlling synaptic organizing complexes.

Key words: neurotrophin-3; PTP $\sigma$; synapse organization; synaptic plasticity; TrkC

\section{Significance Statement}

Although many synaptogenic adhesion complexes have been identified in recent years, little is known about modulatory mechanisms. Here, we demonstrate a novel role of neurotrophin-3 in synaptic assembly and function as a positive modulator of the TrkC-protein tyrosine phosphatase $\sigma$ complex. This study provides new insight into the involvement of neurotrophin signaling in synapse development and plasticity, presenting a molecular mechanism that may underlie previous observations of short- and long-term enhancement of presynaptic function by neurotrophin. Given the links of synaptogenic adhesion molecules to autism and schizophrenia, this study might also contribute to a better understanding of the pathogenesis of these disorders and provide a new direction for ameliorating imbalances in synaptic signaling networks.

\section{Introduction}

Neurotrophins play an important role in the development and plasticity of CNS and PNS by activating neurotrophin receptors and receptor-mediated intracellular signaling cascades (Barbacid, 1994; Chao, 2003; Huang and Reichardt, 2003). Neurotrophin-3 (NT-3) is a member of the nerve growth factor family and mediates trophic effects on neurons, including neuronal differentiation, neurite out- growth, and synapse formation and plasticity (Barbacid, 1994; Huang and Reichardt, 2003; Ramos-Languren and Escobar, 2013). NT-3 binds with highest affinity to TrkC, a neurotrophin receptor tyrosine kinase (RTK), and activates its tyrosine kinase to drive intracellular signaling cascades (Lamballe et al., 1991; Barbacid, 1994). In rodent brain, both NT-3 and TrkC are expressed from embryonic to adult stages and continue to be highly expressed in adult hip- 
pocampus (Maisonpierre et al., 1990; Tessarollo et al., 1993; Lamballe et al., 1994). TrkC is expressed in brain not only as a catalytic isoform but also as a noncatalytic isoform, lacking the tyrosine kinase domain (Valenzuela et al., 1993; Barbacid, 1994). NT-3 binds to both isoforms of TrkC, which share an identical ectodomain (Barbacid, 1994; Urfer et al., 1995). The expression of noncatalytic TrkC is upregulated relative to catalytic TrkC during the second and third postnatal weeks (Valenzuela et al., 1993), the peak period of synaptogenesis, suggesting noncatalytic roles for the TrkC-NT-3 complex in synapse development.

In the CNS, synapse development involves two key cellular steps: (1) physical contact between axon and target neurons by cell adhesion molecules; and (2) chemically matched local assembly of presynaptic and postsynaptic components regulated by synaptic organizers (Shen and Scheiffele, 2010). Thus, synaptic organizing complexes, neuronal adhesion complexes that alone trigger synaptic assembly, have been studied as crucial molecular mediators of synapse development (Siddiqui and Craig, 2011; Takahashi and Craig, 2013). The most well studied synaptic organizing complex is the complex of presynaptic neurexin and postsynaptic neuroligin (Südhof, 2008; Krueger et al., 2012). Consistent with the molecular and functional diversity of CNS synapses, many other synaptic organizing complexes have been identified and characterized. Our recent study identified $\mathrm{TrkC}$ as a synaptic organizer (Takahashi et al., 2011). TrkC acts as a postsynaptic cell adhesion molecule through trans-interaction with presynaptic $\mathrm{PTP} \sigma$, a type IIa receptor-type protein tyrosine phosphatase, for excitatory (glutamatergic) synapse development in brain (Takahashi et al., 2011). This complex acts bidirectionally: presynaptic PTP $\sigma$ induces glutamatergic postsynaptic differentiation, in part via binding to TrkC but also via binding to netrin-G ligand-3, interleukin 1 receptor accessory protein, and Slit- and NTRK-like family (Takahashi and Craig, 2013). Postsynaptic TrkC induces glutamatergic presynaptic assembly via binding to presynaptic PTP $\sigma$ in a tyrosine kinaseindependent manner. The TrkC ectodomain contains an $\mathrm{N}$-terminal leucine-rich repeat (LRR) domain and two membrane proximal Ig-like domains (Ig1 and Ig2; Barbacid, 1994; Huang and Reichardt, 2003). The TrkC Ig2 domain is responsible for NT-3 binding (Urfer et al., 1995, 1998), whereas the TrkC LRR and Ig1 domains are necessary and sufficient for PTP $\sigma$ binding and synaptogenic activity of TrkC to induce presynaptic assembly (Takahashi et al., 2011; Coles et al., 2014; Fig. 1A). Thus, TrkC binds to NT-3 and $\mathrm{PTP} \sigma$ via distinct non-overlapping domains, suggesting potential simultaneous interaction of NT-3 and PTP $\sigma$ with TrkC and modulatory roles of NT-3 on the TrkC-PTP $\sigma$ complex. However, it has not been addressed whether and how NT-3 modulates the synaptogenic activity of the TrkC-PTP $\sigma$ complex.

NT-3 enhances glutamatergic synaptic development and transmission in hippocampal neurons (Kang and Schuman, 1995; comparisons.
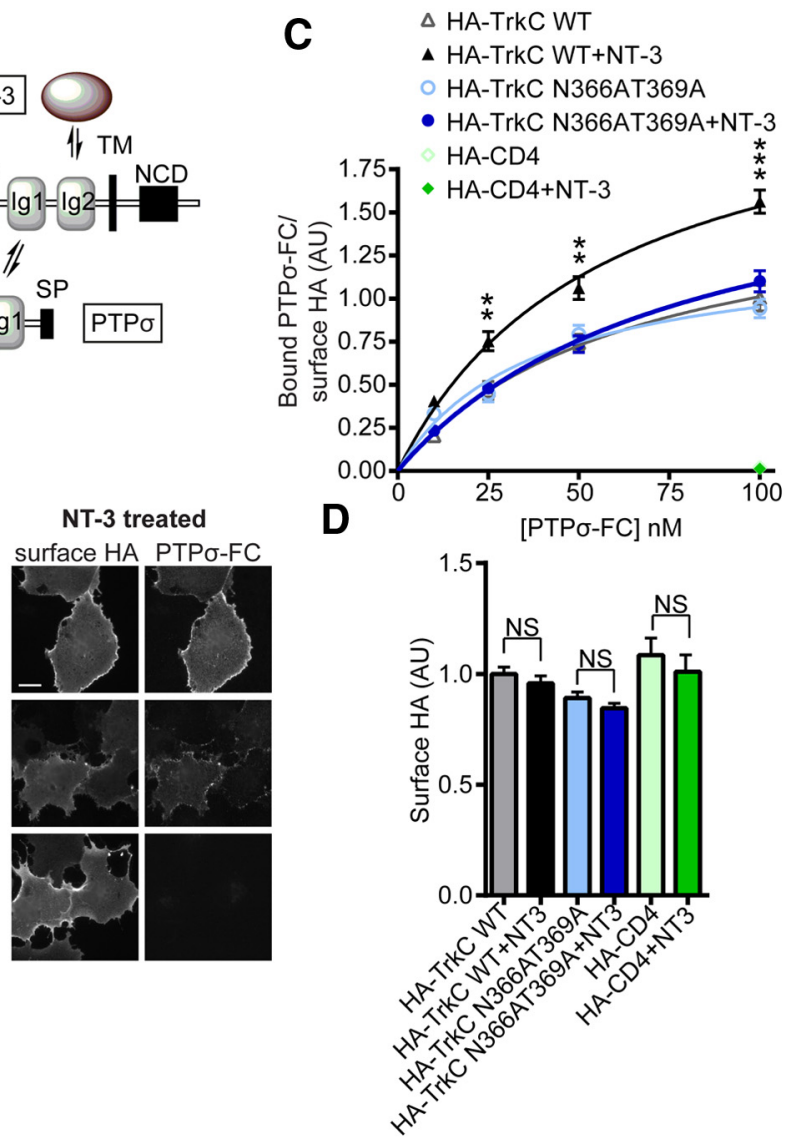

Figure 1. NT-3 enhances the binding of PTP $\sigma$ to cell-surface TrkC. $A$, Schematic domain structures and protein interactions of TrkC noncatalytic isoform, PTP $\sigma$, and NT-3. TrkC LRR and Ig1 are required for PTP $\sigma$ binding, whereas TrkC Ig2 is responsible for NT-3 binding. SP, Signal peptide; CC, cysteine cluster; TM, transmembrane; NCD, noncatalytic domain; FN, fibronectin type-III; D1

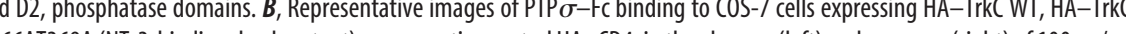

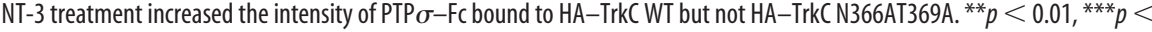
0.001 in two-way ANOVA with Bonferroni's multiple comparisons, $n=20-40$ cells from two independent experiments. $D$ Quantification of surface HA expression in cells analyzed in C. NS, Not significant. One-way ANOVA with Bonferroni's multiple

Vicario-Abejón et al., 1998; Schinder et al., 2000). Here, we hypothesize that NT-3 enhances TrkC-PTP $\sigma$ interaction and hence facilitates glutamatergic presynaptic assembly and function through the TrkC-PTP $\sigma$ complex. In this study, we investigated the effects of NT-3 on TrkC-PTP $\sigma$ interaction and synaptogenic activity of TrkC and revealed a novel role of neurotrophin on synapse organization in a tyrosine kinase-independent manner.

\section{Materials and Methods}

Antibodies. The following mouse monoclonal antibodies were used; anti-HA (IgG2b, 1:500, 12CA5; Roche), anti-dephospho-tau (IgG2a, 1:1000, PCIC6; Millipore), anti-synapsin (IgG1, 1:1000, 45.1; Synaptic Systems), and Oyster-550- or Oyster-650-conjugated anti-synaptotagmin 1 luminal domain (anti-SynTag, IgG1, 1:200, 604.2; Synaptic Systems). For labeling dendrites, we used anti-MAP2 (chicken polyclonal IgY, 1:5000, ab5392; Abcam). As secondary antibodies, we used goat Alexa Fluor 488-conjugated anti-mouse IgG2b, Alexa Fluor 568-conjugated anti-mouse IgG1, and Alexa Fluor 647-conjugated anti-mouse IgG2a (1:500; Invitrogen) and donkey aminomethylcoumarin-conjugated anti-chicken IgY (1:200; Jackson ImmunoResearch). For labeling PTP $\sigma-\mathrm{Fc}$, we used donkey Alexa Fluor 594conjugated anti-human Fc (1:500; Jackson ImmunoResearch).

Plasmids. The extracellular HA-tagged expression plasmids for CD4, TrkC wild-type (WT) and TrkC N366AT369A, for binding and coculture 
assays and the short hairpin RNA (shRNA) vector pLL(syn)CFP shTrkC\#1 for TrkC knockdown were described previously (Takahashi et al., 2011). Noncatalytic TrkC was used to assess kinase-independent functions. We generated the plasmids expressing shRNA-resistant HATrkC $^{\star}$ WT and HA-TrkC ${ }^{\star}$ N366AT369A under the CAG promoter by replacing the coding region of nontagged TrkC of pCAG-TrkCTK(Takahashi et al., 2011) with the HA-tagged coding regions and then introducing five point mutations (underlined: GCAGTAAAAC GAAATTAA), verified previously as resistant against sh-TrkC\#1 (Takahashi et al., 2011). All constructs were verified by nucleotide sequencing.

Cell culture, transfection, and immunocytochemistry. COS-7 cells were cultured in DMEM, high glucose supplemented with $10 \%$ fetal bovine serum and transfected with TransIT-LT1 (Mirus). Dissociated hippocampal neuron cultures were prepared from E18 rat embryos of either sex as described previously (Kaech and Banker, 2006). Animal care and use protocols were approved by the University of British Columbia Animal Care Centre. For neuron transfection, suspended hippocampal cells ( 1 million) were transfected with $2 \mu \mathrm{g}$ of indicated constructs by Amaxa nucleofection (VPG-1003; Program, O-003; Lonza). Neuron cultures were maintained in Neurobasal medium (Invitrogen) with $1 \times$ Glutamax-I, $2 \%$ Neurocult SM1 supplement (StemCell Technologies), and $100 \mu \mathrm{M}$ APV. Fibroblast-neuron coculture assays were performed essentially as described previously (Takahashi et al., 2011, 2012). Briefly, COS-7 cells were transfected, trypsinized $24 \mathrm{~h}$ later, and plated onto neurons at $8 \mathrm{~d}$ in vitro (DIV). After 18-20 h of coculture, the cells were treated with or without 100 $\mathrm{ng} / \mathrm{ml} \mathrm{NT-3} \mathrm{(PHC7036;} \mathrm{Life} \mathrm{Technologies)} \mathrm{for} 1 \mathrm{~h}$ in conditioned neuron culture media at $37^{\circ} \mathrm{C}$. The treated cells were fixed with parafix solution ( $4 \%$ paraformaldehyde and $4 \%$ sucrose in PBS, $\mathrm{pH} 7.4$ ) for $12 \mathrm{~min}$ at room temperature, incubated with blocking solution (PBS plus 3\% BSA and 5\% normal goat serum), and then incubated with anti-HA antibody for labeling surface $\mathrm{HA}$ overnight at $4^{\circ} \mathrm{C}$. The cells were then permeabilized with $0.1 \%$ Triton X-100 in PBS and then stained with primary antibodies for tau, synapsin, and MAP2 for $1 \mathrm{~h}$ at $37^{\circ} \mathrm{C}$ and with secondary antibodies. The coverslips were mounted in elvanol (Tris- $\mathrm{HCl}$, glycerol, and polyvinyl alcohol with 2\% 1,4-diazabi-cyclo[2,2,2] octane).

Production of soluble PTP $\sigma-F c$ protein and binding assays. The production and purification of soluble proteins of PTP $\sigma$ ectodomain fused to human Ig constant region ( $\mathrm{PTP} \sigma-\mathrm{Fc}$ ) were performed as described previously (Takahashi et al., 2011). To assess binding of PTP $\sigma-\mathrm{Fc}$, transfected COS-7 cells were washed with extracellular solution (ECS; $168 \mathrm{~mm}$ $\mathrm{NaCl}, 2.6$ mм KCl, 10 mм HEPES, pH 7.2, 2 mм CaCl, 2 mм $\mathrm{MgCl}_{2}, 10$ $\mathrm{mm}$ D-glucose, and $100 \mu \mathrm{g} / \mathrm{ml} \mathrm{BSA}$ ), incubated for $10 \mathrm{~min}$ at $4^{\circ} \mathrm{C}$ with or without $100 \mathrm{ng} / \mathrm{ml} \mathrm{NT-3}$ in ECS, and then incubated with PTP $\sigma-\mathrm{Fc}$ protein with or without NT-3 in ECS for $50 \mathrm{~min}$ at $4^{\circ} \mathrm{C}$. The treated cells were immunostained for surface $\mathrm{HA}$ and bound $\mathrm{PTP} \sigma-\mathrm{Fc}$ without permeabilization.

Synaptotagmin antibody uptake assay. For assessing changes in recycling vesicles at presynaptic terminals, a synaptotagmin antibody uptake assay was performed essentially as described previously (Malgaroli et al., 1995 ) with some modifications. Live neurons at 9 DIV were first incubated with Oyster-550-conjugated anti-SynTag in conditioned neuron culture media for $1 \mathrm{~h}$ at $37^{\circ} \mathrm{C}$. After washing, the neurons were next incubated with Oyster-650-conjugated anti-SynTag antibody with or without $100 \mathrm{ng} / \mathrm{ml} \mathrm{NT}-3$ for $1 \mathrm{~h}$ at $37^{\circ} \mathrm{C}$. The cells were washed, fixed by parafix solution, and immunostained for surface HA and MAP2 as described above. Changes in presynaptic vesicle recycling during NT-3 treatment were measured by the ratio of Oyster-650 intensity/Oyster-550 intensity as described below.

Fluorescence imaging and image analysis. All image acquisitions, analyses, and quantifications were performed by investigators blind to the experimental condition. Images were acquired on a Zeiss Axioplan2 microscope with a $40 \times, 1.30$ numerical aperture oil-immersion objective or a $63 \times, 1.4$ numerical aperture oil-immersion objective and Orca-Flash 4.0 V2 C11440-22CU camera (Hamamatsu) using MetaMorph imaging software (Molecular Devices) and customized filter sets. For coculture and binding assays, COS-7 cells with similar expression levels of surface HA were chosen throughout all conditions, and image analysis was per- formed as described previously (Takahashi et al., 2011, 2012) using MetaMorph software and NIH ImageJ. Image analysis for the antibody uptake assay was performed using NIH ImageJ. Oyster-550 and Oyster650 channels were both thresholded for synaptotagmin puncta, and a mask of the combined threshold puncta area was used to measure the ratio of Oyster-650 intensity/Oyster-550 intensity through this identical area after subtracting off-cell background. Data and statistical analyses were performed with GraphPad Prism (GraphPad Software). Statistical comparisons were made with one-way or two-way ANOVA with post hoc Bonferroni's multiple comparison, and all data are shown as the mean \pm SEM from two or three independent experiments as indicated in the figure legends. Statistical significance was defined as $p<0.05$.

\section{Results}

\section{NT-3 enhances the interaction between PTP $\sigma$ and cell-surface TrkC}

We first tested whether NT-3 affects the interaction between $\mathrm{PTP} \sigma$ and TrkC in a cell-based binding assay using PTP $\sigma-\mathrm{Fc}$ and COS-7 cells expressing HA-TrkC WT. PTP $\sigma-$ Fc protein specifically bound to COS-7 cells expressing HA-TrkC WT but not a negative control HA-CD4, as reported previously (Takahashi et al., 2011; Fig. 1B). NT-3 treatment seemed to increase the fluorescent intensity of bound $\mathrm{PTP} \sigma-\mathrm{Fc}$ on COS-7 cells expressing HA-TrkC WT (Fig. $1 B$, top right). In quantitative analysis with the application of increasing amounts of PTP $\sigma-\mathrm{Fc}$, NT-3 significantly enhanced binding as seen by an upward shift in the PTP $\sigma-$ Fc binding curve to HA-TrkC WT-expressing COS-7 cells [Fig. $1 C ; 1.50 \pm 0.09$-fold $(p<0.01)$ and $1.57 \pm 0.07$-fold $(p<$ $0.001)$ at 50 and $100 \mathrm{~nm} \mathrm{PTP} \sigma-\mathrm{Fc}$, respectively]. To test whether the enhanced binding of PTP $\sigma-\mathrm{Fc}$ to TrkC by NT-3 is mediated by specific binding of NT-3 to TrkC, we used HA-TrkC containing point mutations that abolish NT-3 binding (HA-TrkC N366AT369A; Urfer et al., 1998). PTP $\sigma-F c$ bound to COS-7 cells expressing HA-TrkC N366AT369A, like HA-TrkC WT. However, NT-3 treatment did not affect the PTP $\sigma-\mathrm{Fc}$ binding curve to COS-7 cells expressing HA-TrkC N366AT369A (Fig. 1C). Additionally, NT-3 had no effect on surface expression of HA-TrkC WT or HA-TrkC N366AT369A (Fig. 1D; all binding was done at $4^{\circ} \mathrm{C}$ to prevent any ligand-induced endocytosis). We also checked whether PTP $\sigma$ binding to TrkC affects the binding of NT-3 to TrkC by Western blot analysis and found no significant effects (data not shown). Thus, NT-3 enhances the interaction between PTP $\sigma$ and cell-surface TrkC via binding to TrkC without affecting TrkC surface expression.

\section{NT-3 facilitates TrkC-induced presynaptic assembly}

We next tested whether NT-3 increases the presynapse-inducing activity of TrkC using a fibroblast-neuron coculture assay. We generated cocultures of hippocampal neurons with COS-7 cells expressing either HA-TrkC WT or HA-TrkC N366AT369A. We applied $100 \mathrm{ng} / \mathrm{ml} \mathrm{NT}-3$ for $1 \mathrm{~h}$ during the last hour of the coculture period and then assessed the synaptogenic activity of TrkC by quantifying the clustering of the presynaptic protein synapsin per area of contact between axons and expressing COS-7 cells (Fig. 2A-D). NT-3 treatment significantly increased the area, intensity, and number of synapsin clusters induced by HA-TrkC WT (e.g., intensity, $1.30 \pm 0.11$-fold, $p<0.05$ ) but not HA-TrkC N366AT369A (Fig. 2A-D). Again, NT-3 had no effect on surface expression of HA-TrkC WT or HA-TrkC N366AT369A (Fig. $2 E)$, nor on axon-COS-7 contact area (data not shown). These data indicate that NT-3 facilitates presynaptic assembly induced by TrkC via binding to TrkC without affecting TrkC surface expression or axonal contact area. 
A
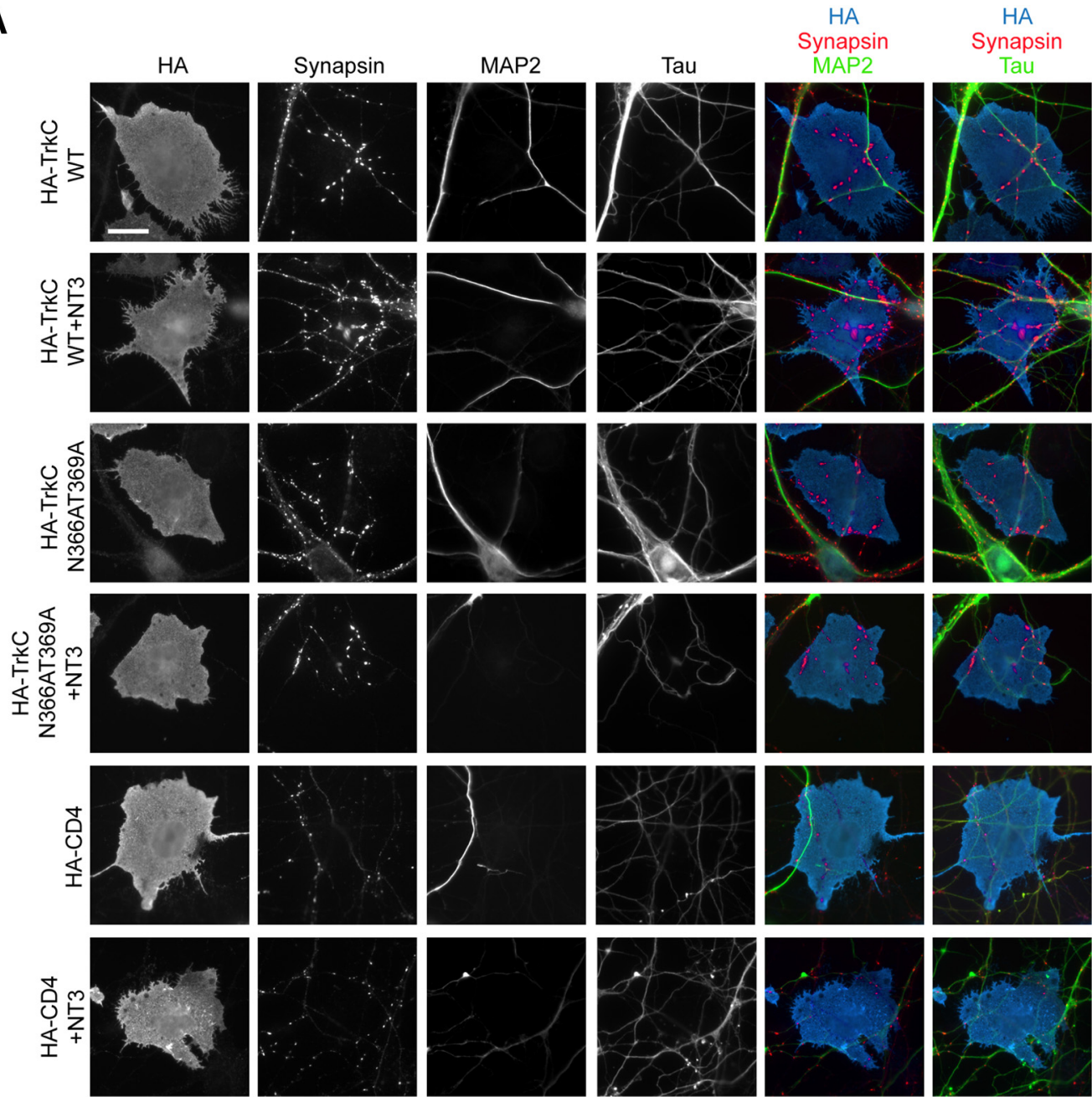

B

C
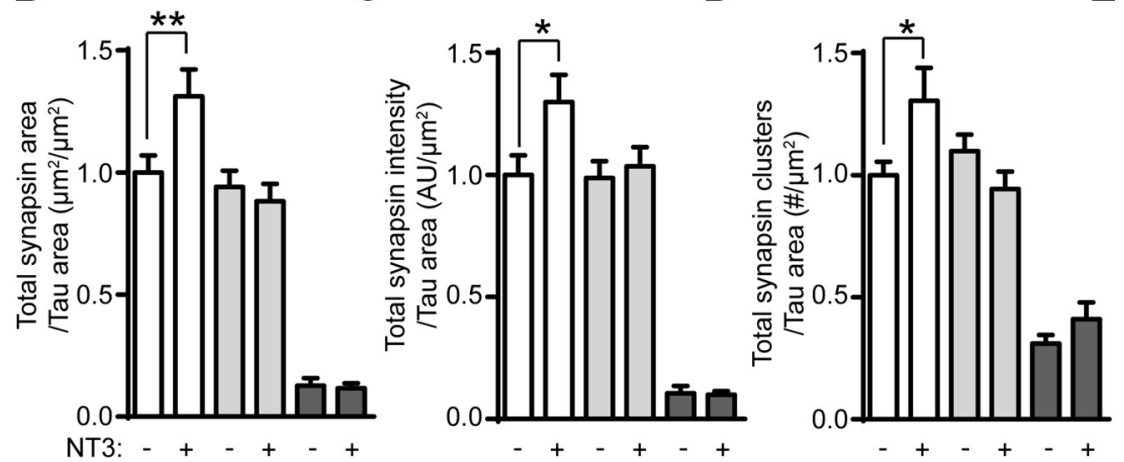

$\mathbf{E}$
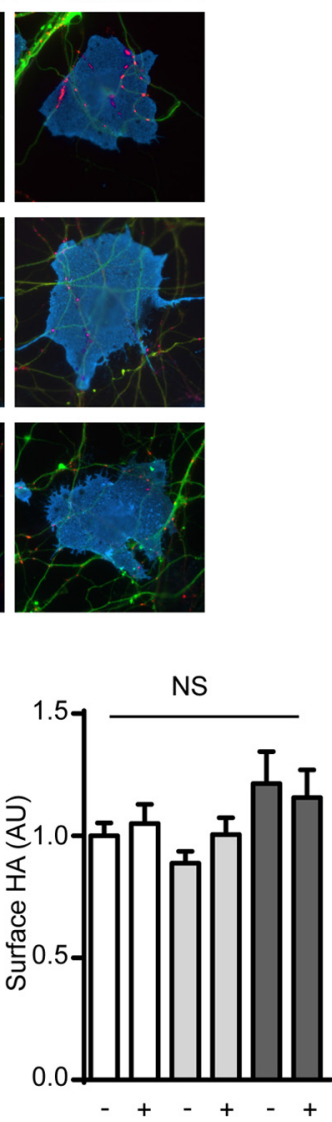

HA-TrkC WT

HA-TrkC N366AT369A

HA-CD4

Figure 2. NT-3 enhances presynaptic induction by TrkC. $A$, Representative coculture images showing induced synapsin clustering in hippocampal neurons by COS-7 cells expressing HA-TrkC WT, HA-TrkC N366AT369A, or HA-CD4 in the presence and absence of $100 \mathrm{ng} / \mathrm{ml} \mathrm{NT-3.} \mathrm{Scale} \mathrm{bar,} 20 \mu \mathrm{m} . \boldsymbol{B}-\boldsymbol{D}$, Quantification of induced synapsin clustering. The area $(\boldsymbol{B})$, total integrated intensity (C), and number (D) of synapsin clusters per axon-COS-7 cell contact area were measured. ${ }^{*} p<0.05,{ }^{* *} p<0.01$ in one-way ANOVA with Bonferroni's multiple comparisons, $n=25-30$ cells from three independent experiments. $\boldsymbol{E}$, Quantification of surface HA expression on COS-7 cells analyzed in $\boldsymbol{B}-\boldsymbol{D}$. NS, Not significant. One-way ANOVA $(p=0.115)$.

NT-3 increases recycling synaptic vesicles at presynaptic terminals via endogenous postsynaptic TrkC

The coculture assay allowed us to test the effects of NT-3 on artificially induced presynaptic terminals. We next evaluated the effects of NT-3 on native functional presynaptic terminals in live hippocampal neurons by monitoring recycling synaptic vesicles. Thus, we measured the differential uptake of antibod- ies that recognize the luminal domain of the synaptic vesicle protein synaptotagmin before and after NT-3 application (for details, see Materials and Methods). NT-3 indeed had a rapid trophic effect on functional presynaptic terminals of native synapses: a $1 \mathrm{~h}$ treatment with NT-3 increased recycling vesicles in untransfected neurons $(\sim 1.3$-fold, $p<0.01$; Fig. $3 A, C)$. The expression of an shRNA construct for TrkC 
A
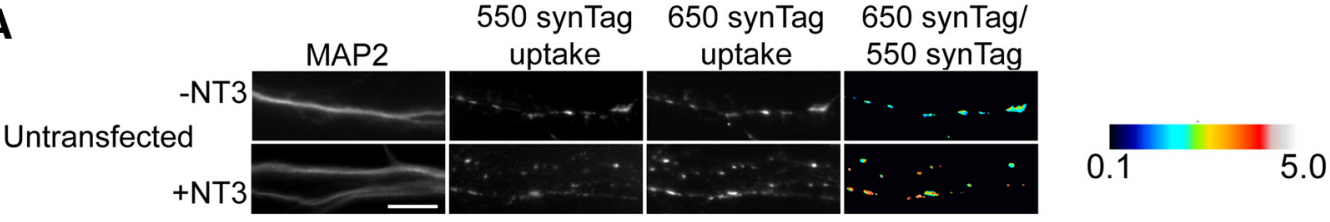

B

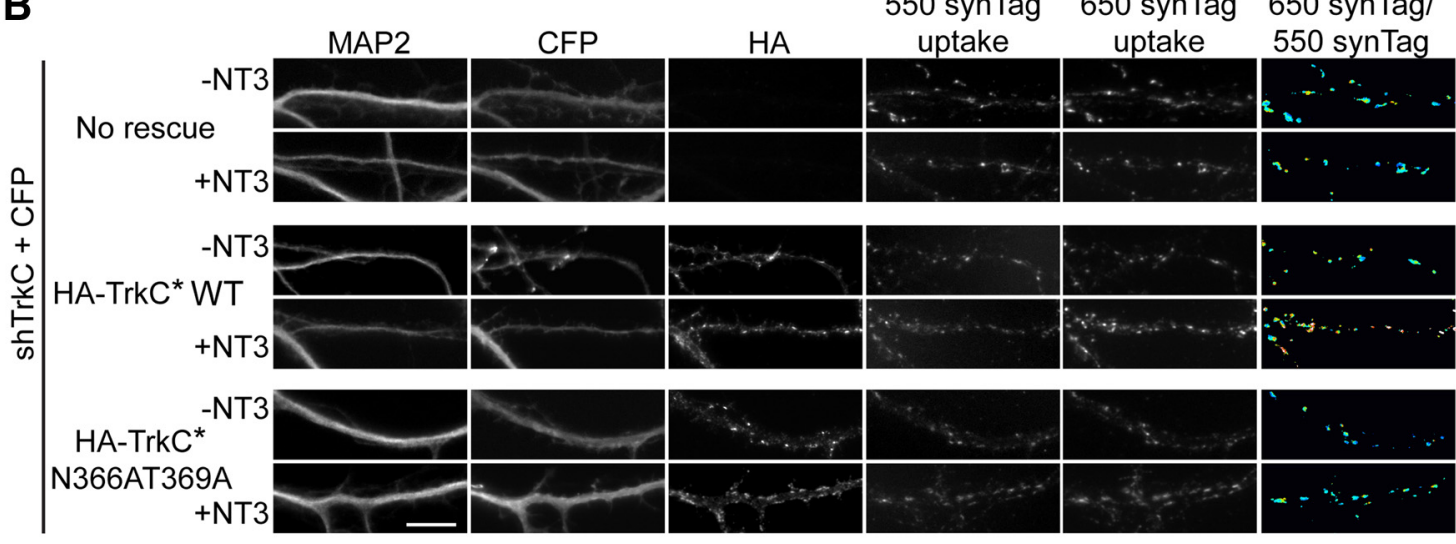

C

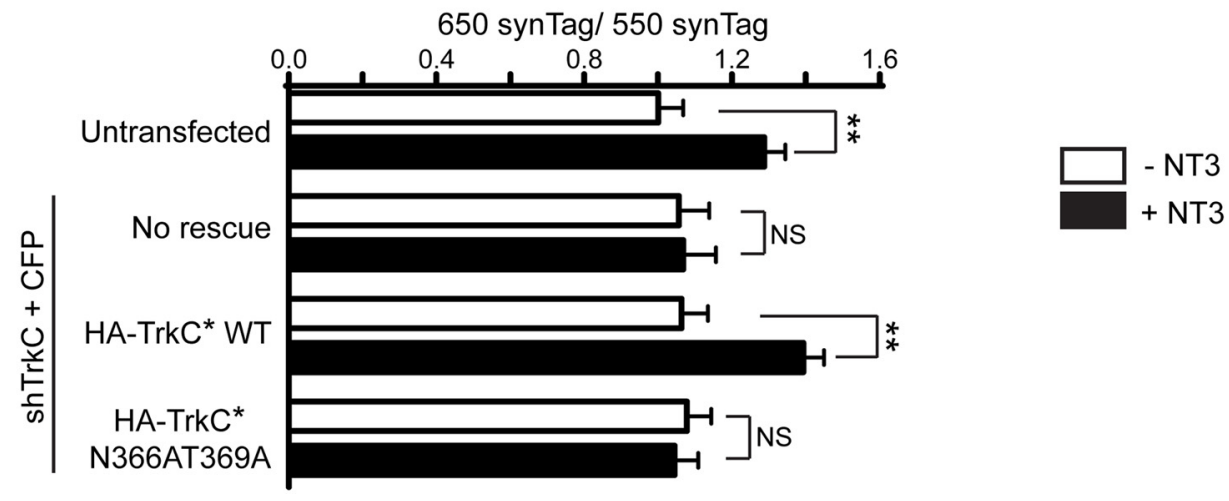

Figure 3. NT-3 increases recycling presynaptic vesicles via endogenous postsynaptic TrkC. Hippocampal neurons were assayed for two rounds of vesicle recycling using anti-SynTag, first with 0yster-550-SynTag to establish baseline and then with 0yster-650-SynTag to assess the effects of NT-3. A, Representative images of differential uptake of SynTag in untransfected hippocampal neurons treated with or without NT-3 (+NT-3 or -NT-3). The right column shows the intensity ratio of 0yster-650/0yster-550 as a heat map with the defined range of $0.1-5$ to visualize changes in presynaptic vesicle recycling. $\boldsymbol{B}$, Representative images of differential uptake of SynTag in neurons transfected with shRNA-expressing vector for TrkC knockdown coexpressing CFP (sh-TrkC + CFP) either alone or together with shRNA-resistant HA-TrkC* WT or HA-TrkC* N366AT369A and treated with or without NT-3. C, Quantification of changes in presynaptic vesicle recycling expressed as the intensity ratio of 0yster-650/0yster-550. ${ }^{* *} p<0.01$ in one-way ANOVA with Bonferroni's multiple comparisons, $n=15-30$ neurons from three independent experiments. Scale bars, $10 \mu \mathrm{m}$.

knockdown in target neurons abolished the NT-3-induced increase in recycling vesicles (Fig. $3 B, C$ ), supporting that endogenous postsynaptic TrkC mediates the trophic effects of NT-3 on presynaptic terminals. This effect of TrkC knockdown was rescued fully by coexpressing shRNA-resistant HA$\mathrm{TrkC}^{\star} \mathrm{WT}(1.39 \pm 0.06$ and $1.06 \pm 0.07$ A.U. with and without NT-3, respectively; $\sim 1.3$-fold increase, $p<0.01$ ) but not shRNA-resistant HA-TrkC* N366AT369A (Fig. 3 B, C). These rescue results not only exclude off-target effects but also indicate that NT-3 binding to postsynaptic TrkC is necessary for the trophic effects of NT-3 on presynaptic terminals, because only the postsynaptic neurons were subjected to TrkC knockdown and rescue, whereas the majority of presynaptic inputs were not manipulated. Furthermore, given that we used TrkC noncatalytic isoform for the rescue, these data together indicate that NT-3 increases recycling vesicles at presynaptic terminals via binding to postsynaptic $\mathrm{TrkC}$ in a tyrosine kinaseindependent manner.

\section{Discussion}

In this study, we show that NT-3 enhances the interaction between PTP $\sigma$ and cell-surface TrkC through binding to TrkC. NT-3 also facilitates the presynapse-inducing activity of TrkC. Furthermore, in live hippocampal neurons, NT-3 rapidly increases recycling vesicles at functional presynaptic terminals of native synapses. The trophic effect of NT-3 on functional presynaptic terminals is mediated by the binding of NT-3 to endogenous postsynaptic $\mathrm{TrkC}$ and independent from the tyrosine kinase activity of TrkC. The TrkC-PTP $\sigma$ complex regulates selectively glutamatergic synapse development (Takahashi et al., 2011). Here we propose that NT-3 acts as a positive modulator for the synaptogenic activity of the TrkC-PTP $\sigma$ complex to enhance glutamatergic presynaptic assembly and function.

Our binding assays show that NT-3 significantly increased PTP $\sigma-\mathrm{Fc}$ protein bound to cell-surface TrkC when 25,50 , or 100 nм PTP $\sigma-\mathrm{Fc}$ was applied. However, because of a technical limitation, in which PTP $\sigma-\mathrm{Fc}$ protein started to aggregate at concen- 
trations higher than $100 \mathrm{nM}$, the binding curves did not reach a saturation state; hence, we could not obtain accurate values of either maximal binding capacity $\left(B_{\max }\right)$ or dissociation constant based on Scatchard analysis. The binding curve of HA-TrkC WT with NT-3 treatment appears likely to obtain a higher saturation level than that of HA-TrkC WT without NT-3, suggesting that NT-3 may increase at least $B_{\max }$. A recent structural study has shown that, in the absence of NT-3, TrkC-PTP $\sigma$ interaction occurs at a 1:1 stoichiometry and involves three major binding interfaces and one potential accessory binding interface of PTP $\sigma$ IgG1-IgG3 to TrkC LRR-IgG1 (Coles et al., 2014). In a future study, it would be of great interest to determine the stoichiometry and structural state of the TrkC-PTP $\sigma$ complex in the presence of NT-3 toward understanding precisely how NT-3 enhances TrkC-PTP $\sigma$ interaction and function. One possibility is that NT-3 binding to the TrkC IgG2 domain may induce a conformational change that creates additional interaction sites between monomeric TrkC and PTP $\sigma$. Alternately, or additionally, it is well established that NT-3 induces the dimerization of TrkC (Barbacid, 1994). The dimeric nature of postsynaptic neuroligin is thought to contribute to its synaptogenic effects (Dean et al., 2003). Thus, dimerization of cell-surface TrkC by NT-3 may contribute to the NT-3 enhancement of TrkC-PTP $\sigma$ interaction and function observed here. Furthermore, it has been reported that NT-3 binding to the TrkC noncatalytic isoform, which we used in this study, induces the recruitment of the scaffold protein tamalin to the TrkC intracellular domain (Esteban et al., 2006). NT-3induced recruitment of tamalin to TrkC may also enhance TrkCPTP $\sigma$ interaction and function by affecting conformation and/or dimerization of TrkC.

Our results suggest that NT-3 facilitates the synaptogenic activity of TrkC by enhancing the binding between cell-surface TrkC and PTP $\sigma$. In our assays, NT-3 treatment induced an $\sim 1.5-$ fold increase in TrkC-PTP $\sigma$ interaction in cell-based binding, a 1.3 -fold increase in presynapse-inducing activity of TrkC in coculture, and a 1.3-fold increase in presynaptic function through TrkC in pure neuron culture. The similarity in these increasing rates supports that NT-3 enhancement of TrkC-PTP $\sigma$ cellsurface interaction mediates the NT-3 enhancement of TrkC synaptogenic activity and of presynaptic function.

Our antibody uptake assays reveal that NT-3 has trophic effects on native functional presynaptic terminals. NT-3 binds not only to TrkC but also to TrkB and p75 with a lower affinity (Barbacid, 1994). However, our knockdown and rescue data indicate that endogenous postsynaptic TrkC fully mediates the NT-3 trophic effects. Together with our binding assays and coculture assays, these experiments further indicate that endogenous postsynaptic TrkC drives transynaptic retrograde signaling independent from TrkC kinase activation to mediate the NT-3 trophic effects. Many previous studies on neurotrophins have demonstrated their trophic roles on synapses through the catalytic activation of their RTKs and RTK-mediated intracellular signaling cascades (Barbacid, 1994; Chao, 2003; Huang and Reichardt, 2003; Park and Poo, 2013). In contrast, our data reveal novel roles of neurotrophin on presynaptic assembly and function in a transynaptic RTK-independent manner, which is one of the most significant findings in this study.

NT-3 has both long-latency long-term and rapid effects on hippocampal excitatory synapse development and function (Lessmann, 1998). Treatment of cultured hippocampal neurons with NT-3 for $72 \mathrm{~h}$ increases functional connectivity between random pairs of neurons by approximately fivefold and also increases functional excitatory transmission, spontaneous vesicle recycling, and total and docked synaptic vesicles per terminal, without altering numbers of synapsin-positive terminals, spine density, or excitatory neuron arbor morphology (Vicario-Abejón et al., 1998; Collin et al., 2001). We suggest that NT-3 may act in this paradigm at least in part by promoting the synaptogenic function of TrkC-PTP $\sigma$. This idea is consistent with the observed independence from glutamate receptor and action potential activity and with the selective enhancement of EPSCs and not IPSCs by NT-3 (Vicario-Abejón et al., 1998; Collin et al., 2001). We observed rapid effects of NT-3, with just a $1 \mathrm{~h}$ treatment, for both recruitment of presynaptic components in coculture and enhanced vesicle recycling in pure neuron culture. These findings are consistent with a role for NT-3 modulation of TrkC-PTP $\sigma$ not just in synapse development but also in plasticity of existing synapses.

NT-3 and brain-derived neurotrophic factor (BDNF) rapidly trigger a long-term potentiation of glutamatergic synaptic transmission (Kang and Schuman, 1995; Schinder et al., 2000). NT-3 and BDNF are also secreted in a neuronal activity-dependent manner (Lessmann et al., 2003). Thus, the enhancement of TrkC-PTP $\sigma$ function by newly secreted NT-3 may be involved in activity-dependent synapse plasticity. A previous study has shown that NT-3 potentiates glutamatergic synaptic transmission in hippocampal neurons via different mechanisms from the potentiation by BDNF (Schinder et al., 2000). Unlike TrkC, TrkB, the major high-affinity receptor for BDNF, does not show synaptogenic activity in cocultures of TrkB-expressing fibroblasts with hippocampal neurons (Takahashi et al., 2011). Therefore, the modulatory effect of NT-3 on the TrkC-PTP $\sigma$ complex would be a key mechanism specific for the potentiation by NT-3. We further suggest that the kinase-independent modulatory function of NT-3 on the TrkC-PTP $\sigma$ complex acts cooperatively with previously described kinase-dependent local protein synthesis (Kang and Schuman, 1995, 1996) to generate the potentiation by NT-3.

In summary, we propose a mechanistic model of NT-3 as a positive modulator of the TrkC-PTP $\sigma$ complex, in which the binding of NT-3 to postsynaptic TrkC enhances trans-interaction between TrkC and PTP $\sigma$ and rapidly facilitates glutamatergic presynaptic assembly and function. Thus, our findings provide a new insight into the role of neurotrophin signaling in synaptic transmission and into the mechanisms modulating synaptic organizing complexes. Given the disease relevance of neurotrophin signaling (Shoval and Weizman, 2005) and the genetic linkages of many synaptic organizers with neuropsychiatric disorders such as autism and schizophrenia (Südhof, 2008; Takahashi and Craig, 2013), our findings might also be helpful for further understanding the pathogenesis of these disorders and ameliorating imbalances in synaptic signaling networks.

\section{References}

Barbacid M (1994) The Trk family of neurotrophin receptors. J Neurobiol 25:1386-1403. CrossRef Medline

Chao MV (2003) Neurotrophins and their receptors: a convergence point for many signalling pathways. Nat Rev Neurosci 4:299-309. CrossRef Medline

Coles CH, Mitakidis N, Zhang P, Elegheert J, Lu W, Stoker AW, Nakagawa T, Craig AM, Jones EY, Aricescu AR (2014) Structural basis for extracellular cis and trans RPTPsigma signal competition in synaptogenesis. Nat Commun 5:5209. CrossRef Medline

Collin C, Vicario-Abejon C, Rubio ME, Wenthold RJ, McKay RD, Segal M (2001) Neurotrophins act at presynaptic terminals to activate synapses among cultured hippocampal neurons. Eur J Neurosci 13:1273-1282. CrossRef Medline

Dean C, Scholl FG, Choih J, DeMaria S, Berger J, Isacoff E, Scheiffele P 
(2003) Neurexin mediates the assembly of presynaptic terminals. Nat Neurosci 6:708-716. CrossRef Medline

Esteban PF, Yoon HY, Becker J, Dorsey SG, Caprari P, Palko ME, Coppola V, Saragovi HU, Randazzo PA, Tessarollo L (2006) A kinase-deficient TrkC receptor isoform activates Arf6-Racl signaling through the scaffold protein tamalin. J Cell Biol 173:291-299. CrossRef Medline

Huang EJ, Reichardt LF (2003) Trk receptors: roles in neuronal signal transduction. Annu Rev Biochem 72:609-642. CrossRef Medline

Kaech S, Banker G (2006) Culturing hippocampal neurons. Nat Protoc 1:2406-2415. CrossRef Medline

Kang H, Schuman EM (1995) Long-lasting neurotrophin-induced enhancement of synaptic transmission in the adult hippocampus. Science 267:1658-1662. CrossRef Medline

Kang H, Schuman EM (1996) A requirement for local protein synthesis in neurotrophin-induced hippocampal synaptic plasticity. Science 273: 1402-1406. CrossRef Medline

Krueger DD, Tuffy LP, Papadopoulos T, Brose N (2012) The role of neurexins and neuroligins in the formation, maturation, and function of vertebrate synapses. Curr Opin Neurobiol 22:412-422. CrossRef Medline

Lamballe F, Klein R, Barbacid M (1991) trkC, a new member of the trk family of tyrosine protein kinases, is a receptor for neurotrophin-3. Cell 66:967-979. CrossRef Medline

Lamballe F, Smeyne RJ, Barbacid M (1994) Developmental expression of trkC, the neurotrophin-3 receptor, in the mammalian nervous system. J Neurosci 14:14-28. Medline

Lessmann V (1998) Neurotrophin-dependent modulation of glutamatergic synaptic transmission in the mammalian CNS. Gen Pharmacol 31:667674. CrossRef Medline

Lessmann V, Gottmann K, Malcangio M (2003) Neurotrophin secretion: current facts and future prospects. Prog Neurobiol 69:341-374. CrossRef Medline

Maisonpierre PC, Belluscio L, Friedman B, Alderson RF, Wiegand SJ, Furth ME, Lindsay RM, Yancopoulos GD (1990) NT-3, BDNF, and NGF in the developing rat nervous system: parallel as well as reciprocal patterns of expression. Neuron 5:501-509. CrossRef Medline

Malgaroli A, Ting AE, Wendland B, Bergamaschi A, Villa A, Tsien RW, Scheller RH (1995) Presynaptic component of long-term potentiation visualized at individual hippocampal synapses. Science 268:1624-1628. CrossRef Medline

Park H, Poo MM (2013) Neurotrophin regulation of neural circuit development and function. Nat Rev Neurosci 14:7-23. CrossRef Medline

Ramos-Languren LE, Escobar ML (2013) Plasticity and metaplasticity of adult rat hippocampal mossy fibers induced by neurotrophin-3. Eur J Neurosci 37:1248-1259. CrossRef Medline
Schinder AF, Berninger B, Poo M (2000) Postsynaptic target specificity of neurotrophin-induced presynaptic potentiation. Neuron 25:151-163. CrossRef Medline

Shen K, Scheiffele P (2010) Genetics and cell biology of building specific synaptic connectivity. Annu Rev Neurosci 33:473-507. CrossRef Medline

Shoval G, Weizman A (2005) The possible role of neurotrophins in the pathogenesis and therapy of schizophrenia. Eur Neuropsychopharmacol 15:319-329. CrossRef Medline

Siddiqui TJ, Craig AM (2011) Synaptic organizing complexes. Curr Opin Neurobiol 21:132-143. CrossRef Medline

Südhof TC (2008) Neuroligins and neurexins link synaptic function to cognitive disease. Nature 455:903-911. CrossRef Medline

Takahashi H, Craig AM (2013) Protein tyrosine phosphatases PTPdelta, PTPsigma, and LAR: presynaptic hubs for synapse organization. Trends Neurosci 36:522-534. CrossRef Medline

Takahashi H, Arstikaitis P, Prasad T, Bartlett TE, Wang YT, Murphy TH, Craig AM (2011) Postsynaptic TrkC and presynaptic PTPsigma function as a bidirectional excitatory synaptic organizing complex. Neuron 69:287-303. CrossRef Medline

Takahashi H, Katayama K, Sohya K, Miyamoto H, Prasad T, Matsumoto Y, Ota M, Yasuda H, Tsumoto T, Aruga J, Craig AM (2012) Selective control of inhibitory synapse development by Slitrk3-PTPdelta transsynaptic interaction. Nat Neurosci 15:389-398:S1-S2. CrossRef Medline

Tessarollo L, Tsoulfas P, Martin-Zanca D, Gilbert DJ, Jenkins NA, Copeland NG, Parada LF (1993) trkC, a receptor for neurotrophin-3, is widely expressed in the developing nervous system and in non-neuronal tissues. Development 118:463-475. Medline

Urfer R, Tsoulfas P, O'Connell L, Shelton DL, Parada LF, Presta LG (1995) An immunoglobulin-like domain determines the specificity of neurotrophin receptors. EMBO J 14:2795-2805. Medline

Urfer R, Tsoulfas P, O'Connell L, Hongo JA, Zhao W, Presta LG (1998) High resolution mapping of the binding site of TrkA for nerve growth factor and TrkC for neurotrophin-3 on the second immunoglobulin-like domain of the Trk receptors. J Biol Chem 273:5829-5840. CrossRef Medline

Valenzuela DM, Maisonpierre PC, Glass DJ, Rojas E, Nuñez L, Kong Y, Gies DR, Stitt TN, Ip NY, Yancopoulos GD (1993) Alternative forms of rat TrkC with different functional capabilities. Neuron 10:963-974. CrossRef Medline

Vicario-Abejón C, Collin C, McKay RD, Segal M (1998) Neurotrophins induce formation of functional excitatory and inhibitory synapses between cultured hippocampal neurons. J Neurosci 18:7256-7271. Medline 